\title{
AVALIAÇÃo ANATOMOPATOLÓGICA E CAUSAS DE MEGAESÔFAGO EM CÃES
}

\author{
SANTOS, Romeu Moreira dos ${ }^{1}$ \\ BONICHELLI, Rosângela K. Jomori ${ }^{2}$ \\ CAMPOS, Aline Gomes de ${ }^{2}$
}

RESUMO: O esôfago é um órgão tubular músculo-membranoso que transporta o alimento da faringe até o estômago, sendo importante para o fluxo alimentar. Está sujeito a algumas afecções, dentre as mais comuns em cães, tem-se o megaesôfago, doença relacionada a várias etiologias. Assim, o objetivo desse estudo foi avaliar macroscopicamente esôfagos de cães portadores de megaesôfago (ME) comparativamente ao de não portadores (NME) desta patologia. Foram analisados oito cães, sendo quatro ME e quatro NME, dos quais dois animais eram de porte grande e dois de porte pequeno, em cada grupo. $\mathrm{O}$ material foi coletado de animais que foram submetidos à necropsia no Hospital Veterinário da Faculdade Dr. Francisco Maeda (FAFRAM) - Ituverava, SP. Macroscopicamente, os cães portadores de megaesôfago apresentaram dilatação deste órgão, com hiperemia, consistência flácida ou rígida e, em um caso, presença de corpo estranho. Neste estudo, podemos concluir que o megaesôfago têm alterações patológicas que se apresentam de formas diferentes para cada tipo de etiologia.

Palavra-Chave: Esôfago. Fraqueza esofágica. Regurgitação. Cão.

SUMMARY: The esophagus is a tubular muscle-membranous organ that carries food from the pharynx to the stomach, which is important for the flow of food. It is subject to some affections, among the most common in dogs, has megaesophagus, disease related to multiple etiologies. The objective of this study was evaluate macroscopically esophagi of dogs with megaesophagus (ME) compared to non-carriers (NME) of this condition. Were analyzed eight dogs, four ME and four NME, of which two animals were of big size and two small size in each group. The material was collected from animals that were autopsied at the Veterinary Hospital of the Faculty Dr. Francisco Maeda (FAFRAM) - Ituverava, SP. Macroscopically the dogs with megaesophagus had dilatation of this organ, with hyperemia, flaccid or rigid consistency, and in one cases, the presence a foreign body. In this study, we can conclude that megaesophagus have pathological alterations that are presented in different forms for each type of etiology.

Keywords: Esophagus. Esophageal weakness. Regurgitation. Dog.

\section{INTRODUÇÃO}

O esôfago é um órgão tubular músculo-membranoso, distensível que conduz os alimentos da orofaringe ao estômago (MILLER; EVANS, 1993). Inicia-se dorsalmente à cartilagem cricóide da laringe e acompanha a traquéia ao longo do pescoço passando pelo hiato esofágico até o estômago, dividindo-se em três porções: cervical, torácica e abdominal (DYCE et al., 1997). É um órgão importante no fluxo alimentar e está sujeito a algumas alterações que afetam sua função dentre elas, nos cães, está à fraqueza

\footnotetext{
${ }^{1}$ Médico Veterinário, Mestrando da Universidade Estadual Paulista "Julio de Mesquita Filho (UNESP), Campus de Jaboticabal-SP. Autor Correspondente: romeumdsantos@ hotmail.com.

${ }^{2}$ Docente do Curso de Medicina Veterinária da Faculdade Dr. Francisco Maeda (FAFRAM).
} 
esofágica ou como é conhecida megaesôfago. Essa afecção pode ser definida como dilatação e disfunção/paralisia do esôfago e a patogenia é caracterizada por falha progressiva de ondas peristálticas (DIMSKI; SHERDING, 2003), constituindo a principal causa de regurgitação através da boca ou narinas. Nesta patologia, a motilidade esofágica encontra-se diminuída ou ausente, resultando no acúmulo e na retenção de alimento e/ou líquido no esôfago (LONGSHORE, 2008), podendo ser idiopático congênito ou adquirido e, ainda de caráter secundário (JONES, 2000). O objetivo deste trabalho foi avaliar macroscopicamente esôfagos de caninos portadores e não portadores de megaesôfago investigando as possíveis causas desta doença.

\section{MATERIAL E MÉTODOS}

O estudo foi desenvolvido no Laboratório de Patologia Animal do Hospital Veterinário da Faculdade Dr. Francisco Maeda (FAFRAM)/ FE, em Ituverava, SP, onde oito cães SRD, de ambos os sexos e diferentes idades, foram submetidos ao exame necroscópico seguindo-se as coletas do esôfago para posterior análise anatomopatológica. Foram analisados quatro animais portadores de megaesôfago e quatro não portadores.

\section{RESULTADOS}

Entre cães portadores de megaesôfago (animais 1, 2, 3 e 4) foram observadas diferentes alterações patológicas que puderam ser associadas a etiologias diversas (Tabela 1).

O animal 1 (cão adulto) apresentou o esôfago dilatado em toda sua porção, estando acentuada na região distal e com sinais de hiperemia passiva. Não foram evidenciadas alterações secundárias que pudessem identificar a etiologia deste megaesôfago, que foi classificado como megaesôfago idiopático adquirido. Também foram evidenciados neste animal sinais de megacólon e hipertrofia cardíaca.

No animal 2 (cão adulto), o esôfago mostrou-se dilatado apenas na região torácica caudal próximo à base do coração, com sinais de estenose, coloração pálida, consistência flácida de forma difusa e acentuada, presença de esofagite focal e resíduos alimentares nesta mesma porção. Já na região cervical, o esôfago mostrou-se normal. O megaesôfago, neste caso, ocorreu devido à persistência do arco aórtico direito (PAAD).

O animal 3 (cão adulto) apresentou dilatação do esôfago em toda a extensão, com hiperemia passiva de forma difusa e acentuada, consistência rígida e coloração cianótica acentuada. No exame necroscópico deste cão foi encontrado um tecido de algodão dentro da luz do órgão, fato que, provavelmente, levou a uma esofagite crônica de caráter acentuada. A patologia, neste caso, foi associada ao megaesôfago secundário.

O animal 4 era um cão com três meses de idade e apresentou o esôfago dilatado em toda sua 
porção, acentuadamente na região média torácica, com vasos em hiperemia passiva de forma difusa e acentuada, camadas delgadas, com consistência flácida, coloração avermelhada de forma difusa e acentuada e presença de muco com resíduos alimentares. Neste cão, o megaesôfago foi classificado como idiopático congênito. Os animais não portadores de megaesôfago (NME) apresentaram ausência de dilatação esofágica, tecidos de consistência normal e ausência de conteúdo alimentar. Adicionalmente, nesses cães foram observadas algumas alterações como hiperemia passiva difusa e discreta. No histórico clínico desses animais constatou-se, entre os sintomas, a êmese, o que pode estar associado à ocorrência dessas alterações patológicas.

Tabela 1: Achados macroscópicos e etiologias relacionadas ao megaesôfago dos cães submetidos ao exame necroscópico no Hospital Veterinário da FAFRAM/ FE, Ituverava, SP.

\begin{tabular}{clcc}
\hline Animal & \multicolumn{1}{c}{ Achados macroscópicos } & Etiologias \\
\hline Animal 1 & $\begin{array}{l}\text { Megaesôfago associado à megacólon e hipertrofia } \\
\text { cardíaca }\end{array}$ & Idiopático adquirido \\
Animal 2 & $\begin{array}{l}\text { Megaesôfago associado à persistência do arco aórtico } \\
\text { direito }\end{array}$ & Secundário \\
Animal 3 & $\begin{array}{l}\text { Megaesôfago associado à presença de corpo estranho na } \\
\text { luz do órgão }\end{array}$ & Secundário \\
Animal 4 & $\begin{array}{l}\text { Megaesôfago associado à caquexia, pneumonia } \\
\text { aspirativa e presença de conteúdo alimentar }\end{array}$ & Idiopático congênito \\
\hline
\end{tabular}

\section{DISCUSSÃO}

Nesse trabalho descrevem-se anatomopatologicamente casos de megaesôfago de diferentes etiologias. No animal 1, o megasôfago de caráter idiopático foi classificado como adquirido por se tratar de um animal adulto. Os achados de megacólon e hipertrofia cardíaca neste cão permitem suspeitar-se de infecção por Trypanosoma cruzi, o que será confirmado após estudo imunohistoquímico. Earlam (1972) descreveu quadros semelhantes em cães com "doenças de Chagas". No animal em que se observou o megaesôfago secundário por PAAD (animal 2), a dilatação esofágica ocorreu apenas na região cranial à estenose, região mais comum para a ocorrência de dilatação provocada por esta alteração (Dupla, 2010). Já Oliveira (2004) encontrou dilatação esofágica tanto cranial quanto caudal à lesão provocada pela PAAD. A etiologia do megaesôfago do animal 3 foi classificado como secundário, devido a obstrução esofágica causada pelo tecido de algodão associado a esofagite crônica acentuada, está de acordo à descrição de Washabau (2004), que menciona a ocorrência do megaesôfago pela presença constante de corpo estranho no interior do órgão. No animal 4, o megaesôfago foi classificado como idiopático congênito, pois tratava-se de um animal jovem e que evoluiu à óbito devido à regurgitação e a dificuldade de alimentar-se, apresentando ainda caquexia e pneumonia aspirativa. Relatos mencionados por Willard 
et al. (2001); Longshore (2008) e Oliveira (2010) descrevem tais sinais clínicos como principais causas de mortalidade em cães com megaesôfago.

\section{CONCLUSÃO}

As avaliações anatomopatológicas permitem concluir que os cães portadores de megaesôfago apresentam o órgão alvo dilatado podendo ocorrer em toda a extensão ou apenas em regiões específicas, com ou sem rigidez.

As possíveis etiologias do megaesôfago nos casos avaliados tiveram causas diversas e puderam ser identificadas pelos exames macroscópicos.

\section{REFERÊNCIAS}

DIMSKI, D. S.; SHERDING, R. G. Doenças gastrointestinais: regurgitação. In: FENNER, W. R.. Consulta rápida em clínica veterinária. 3. ed. Rio de Janeiro: Guanabara Koogan, Cap. 20, p. 247-249, 2003.

DUPLA, J. B. Diseases of the Esophagus. Disponível em: HTTP://www.vin.com/proceedings/Proceedings.plx?CID=WSAVA2002\&PID=2579. Acesso em: $31 \mathrm{dez}$. 2010.

DYCE, K. M.; SACK, W. O.; WENSING, C. J. G. O aparelho digestivo: o esôfago. In: DYCE, K. M.; SACK, W. O.; WENSING, C. J. G. Tratado de Anatomia Veterinária. 2. ed. Rio de Janeiro: Guanabara Koogan, Cap. 3, p. 95-96, 1997.

EARLAM, R. J. Gastrointestinal Aspects of Chagas' Disease. The American Journal Of Digestive Diseases. The U. S. A. v. 17, n. 6, p. 559-571, 1972.

JONES, T. C. Sistema digestivo. In: JONES, T. C.; HUNT, R. D.; KING, N. W. Patologia Veterinária. 6. ed. São Paulo: Manole, Cap. 23, p. 1076-1077, 2000.

KONIG, H. E.; LIEBICH, H. Aparelho digestório. In: KONIG, H. E.; LIEBICH, H. Anatomia dos Animais Domésticos. São Paulo: Artmed, v. 2, cap. 7, p. 40-42, 2004.

LONGSHORE, R. C. Megaesôfago. In: TILLEY, L. P.; SMITH, F. W. K. Consulta Veterinária em 5 minutos: espécies canina e felina. 3. ed. São Paulo: Manole, p. 950-951, 2008.

MILLER, M. E.; EVANS, H. E. The digestive apparatus and the abdomen. In: MILLER M. E., EVANS, H. E. Miller's Anatomy of the Dog. 3. ed. Philadelphia: WB Saunders, p.411-507, 1993.

OLIVEIRA, E. C. et al. Persistência do arco aórtico direito em um cão - Relato de caso. Faculdade de Zootecnia, Veterinária e Agronomia, Uruguaiana, v.11, n.1, p.174-180, 2004.

OLIVEIRA, M. R. C. M. Megaesôfago. Disponível em: http://www.kennelclub.com.br/ Acesso em: 29 dez. 2010. 
WASHABAU, R. J. Doenças do esôfago: Megaesôfago. In: ETTINGER, S. J.; FELDMAN, E. C.

Tratado de medicina interna veterinária: Doenças do cão e do gato. 5. ed. Rio de Janeiro: Guanabara Koogan, Cap. 135, p. 1205-1217, 2004.

WILLARD, M. D. Digestive System Disorders: Disorders of the Oral Cavity, Pharynx, and Esophagus. In: NELSON, R.W.; COUTO, C. G. Small Animal Internal Medicine. 4. ed. St. Louis, Missouri: Mosby Elsevier, Cap. 31, p. 419-421, 2009. 
